EPJ Web of Conferences 41, 05010 (2013)

DOI: $10.1051 /$ epjconf/20134105010

(C) Owned by the authors, published by EDP Sciences, 2013

\title{
High spin $\leftrightarrow$ low spin ultrafast excitation and relaxation of an isolated iron(II) complex
}

\author{
G. Galle ${ }^{1}$, J. Tribollet ${ }^{1}$, G. Jonusauskas ${ }^{1}$, M. Tondusson ${ }^{1}$, C. Mauriac ${ }^{2}$, J.F. Létard ${ }^{2}$ and E. Freysz ${ }^{1}$ \\ ${ }^{1}$ University of Bordeaux, CNRS-UMR 5798, LOMA, 351 cours de la Libération, Talence 33405, \\ France \\ ${ }^{2}$ CNRS, University of Bordeaux, ICMCB, 87 avenue du, Dr A. Schweitzer,Pessac, F-33608, France
}

\begin{abstract}
Picosecond and femtosecond time resolved pump-probe experiments make it possible to study both the low spin (LS) to high spin (HS) and high spin to low spin excitation and relaxation processes in the same isolated iron(II) complex. We demonstrate that both LS $\rightarrow$ HS and HS $\rightarrow$ LS can be recorded by changing the pump wavelength and occur on the same time scale.
\end{abstract}

Among spin crossover (SCO) compounds, iron(II) complexes are of particular interest. For iron(II) SCO crystals, it has been shown that optical excitations along the weak d-d singlet $\left({ }^{1} \mathrm{~A}_{1}, \mathrm{~S}=0\right)$ Low Spin (LS) to triplet $\left({ }^{1,3} \mathrm{~T}, \mathrm{~S}=1\right)$ or quintet $\left({ }^{5} \mathrm{~T}_{2}, \mathrm{~S}=2\right)$ High Spin (HS) to quintet $\left({ }^{5} \mathrm{E}\right)$ optical transition of iron(II) ion can drive back and forth iron(II) from LS to HS states [1]. On the other hand, McGarvey et al. were the first to discover that in a solution of iron(II) complexes, the HS state could be populated at the expense of the LS state by pulsed laser excitation [2]. In this case, the doorway to the HS state is usually achieved via the singlet metal-to-ligand-charge-transfer ( ${ }^{1}$ MLCT) that exhibits strong absorption bands in the visible spectrum. The latter process has been shown to be very efficient and, in less than $300 \mathrm{fs}, \sim 100 \%$ of the complexes excited in the ${ }^{1}$ MLCT state relax toward the ${ }^{5} \mathrm{~T}_{2}$ state [3-4]. The associated experiments resolved a long-standing issue about the population mechanism of quintet states in iron(II)-based complexes, which were identified as a simple ${ }^{1} \mathrm{MLCT} \rightarrow{ }^{3} \mathrm{MLCT} \rightarrow{ }^{5} \mathrm{~T}_{2}$ cascade starting from the LS state [3]. However nobody has, to the best of our knowledge, demonstrated the reverse phenomenon: i.e. the HS to LS photo-excitation of isolated iron(II) complexes in a solution. Therefore for isolated molecules in solution, one can question if the absence of cooperative phenomena does not forbid such a photo-switching. Hereafter, using picosecond and femtosecond time resolved experiments, we demonstrate that it is indeed possible to study both the LS $\rightarrow$ HS and HS $\rightarrow$ LS excitation and relaxation processes in a solution of iron(II) complexes. Both processes are shown to occur in less than $300 \mathrm{fs}$. The relaxation pathways of the photo-excited complexes are presented and discussed.

We studied, at room temperature, two very similar $\left[\mathrm{Fe}(\text { phen })_{3}\right]^{2+}$ and $\left[\mathrm{Fe}\left(2 \mathrm{CH}_{3} \text {-phen }\right)_{3}\right]^{2+}$ (phen=1,10-phenantroline) complexes dissolved in acetonitrile. Under these conditions, the $\left[\mathrm{Fe}(\text { phen })_{3}\right]^{2+}$ complexes are in the LS state whereas for the $\left[\mathrm{Fe}\left(2 \mathrm{CH}_{3} \text {-phen }\right)_{3}\right]^{2+}$ solution, $\sim 80 \%$ (resp. $\sim 20 \%$ ) of the complexes are in the HS (resp. LS) state [5]. We have previously shown that the excitation of $\left[\mathrm{Fe}(\mathrm{phen})_{3}\right]^{2+}$ solution by $\sim 100 \mathrm{fs}$ pulses centered at $500 \mathrm{~nm}$ makes it possible to promote complexes from the LS to the HS state in less than $300 \mathrm{fs}$ [8]. For these complexes, the

This is an Open Access article distributed under the terms of the Creative Commons Attribution License 2.0, which permits unrestricted use, distribution, and reproduction in any medium, provided the original work is properly cited. 
photo-induced HS state that relaxes in $1.6 \pm 0.4 \mathrm{~ns}$ absorbs at $\lambda \sim 330 \mathrm{~nm}$. This absorption was attributed to the quintet $\left({ }^{5} \mathrm{~T}_{2}\right)$ metal-to-ligand-charge-transfer $\left({ }^{5} \mathrm{MLCT}\right)$. Thus, one may consider to perform transient $\mathrm{LS} \rightarrow \mathrm{HS}$ or $\mathrm{HS} \rightarrow \mathrm{LS}$ photo-excitation by exciting the $\left[\mathrm{Fe}\left(2 \mathrm{CH}_{3} \text {-phen }\right)_{3}\right]^{2+}$ at $\lambda \sim 500 \mathrm{~nm}$ or $\lambda \sim 330 \mathrm{~nm}$ respectively. Firstly, we excited the $\left[\mathrm{Fe}\left(2 \mathrm{CH}_{3} \text {-phen }\right)_{3}\right]^{2+}$ complexes with picosecond pulses centered at $\lambda=500 \mathrm{~nm}$ and recorded the transient optical density of the sample versus the pump delay. The associated absorption spectrogram recorded by a streak camera is shown in Figure 1a. In good agreement with $\left[\mathrm{Fe}(\mathrm{phen})_{3}\right]^{2+}$, upon excitation we noticed a bleaching of the singlet metal-to-ligand-charge-transfer band that is centered at $\lambda \sim 500 \mathrm{~nm}$. This bleaching relaxes in $\sim 3.6 \pm 0.2 \mathrm{~ns}$ (Figure 1c). This clearly indicates promotion of $\left[\mathrm{Fe}\left(2 \mathrm{CH}_{3} \text {-phen }\right)_{3}\right]^{2+}$ complexes from LS to HS state upon such a pulsed excitation.
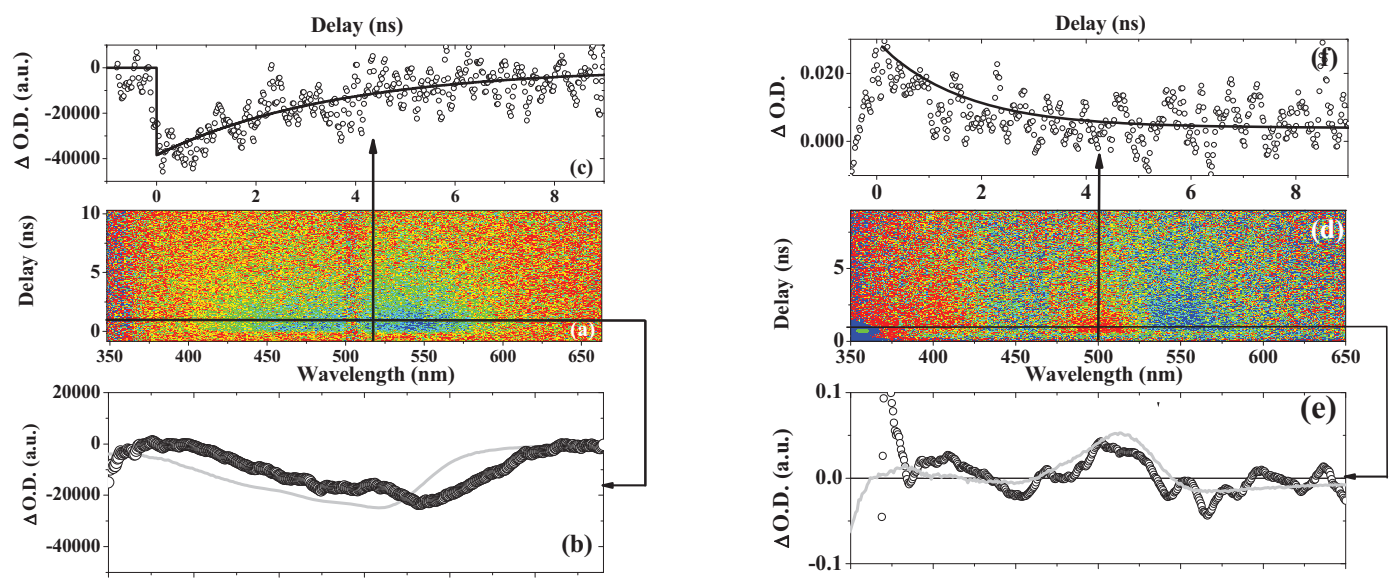

Fig. 1: Spectro-temporal evolution of the differential absorption spectrum of the $\left[\mathrm{Fe}\left(2 \mathrm{CH}_{3} \text {-phen }\right)_{3}\right]^{2+}$ complex after its excitation at (a) $\lambda=500 \mathrm{~nm}$ and (d) $\lambda=355 \mathrm{~nm}$. The black dots in (b) and (e) are the differential absorption spectrum recorded $\sim 1 \mathrm{~ns}$ after an excitation. The grey lines are the absorption of $\left[\mathrm{Fe}(\mathrm{phen})_{3}\right]^{2+}$ in the LS state and the absorption obtained subtracting the weighted stationary absorption spectra of $\left[\mathrm{Fe}(\text { phen })_{3}\right]^{2+}$ and $\left[\mathrm{Fe}\left(2 \mathrm{CH}_{3} \text {-phen }\right)_{3}\right]^{2+}$ respectively. Fig. (c) and (f) present the experimental data and the mono exponential fits of the relaxation kinetic of the differential absorption spectrum at the selected wavelength.

We performed the same experiment exciting the solution at $\lambda=355 \mathrm{~nm}$. Figure $1 \mathrm{~d}$ shows the recorded spectrogram. As shown in Figure 1e, the narrower width of the weak absorption band recorded at $\lambda=500 \mathrm{~nm}$ upon excitation as well as the slight bleaching at the edges of the ${ }^{1} \mathrm{~A}_{1} \rightarrow{ }^{1}$ MLCT band invalidates a pure HS to LS photo-switching. However, as shown in Figure 1e, one could reproduce this transient spectrogram by subtracting the weighted stationary absorption spectra of $\left[\mathrm{Fe}(\text { phen })_{3}\right]^{2+}$ and $\left[\mathrm{Fe}\left(2 \mathrm{CH}_{3} \text {-phen }\right)_{3}\right]^{2+}$ complexes. This indicates that the transient recorded spectra can be accounted by a slight increase of the population of LS state. In fact upon excitation two opposite processes are taking place. On the one hand, we previously showed the photo-induced HS of $\left[\mathrm{Fe}\left(2 \mathrm{CH}_{3} \text {-phen }\right)_{3}\right]^{2+}$ do absorbs at $\lambda=330 \mathrm{~nm}$ [6]. Hence, one can populate the LS state along the excitation of the quintet $\left({ }^{5} \mathrm{~T}_{2}\right)$ to metal-to-ligand-charge-transfer $\left({ }^{5} \mathrm{MLCT}\right)$ band that subsequently relax toward the LS state. On the other hand, the pump excitation could also results in a promotion of the $\left[\mathrm{Fe}\left(2 \mathrm{CH}_{3} \text {-phen }\right)_{3}\right]^{2+}$ complexes from the LS to HS state. Indeed, we have shown that the kinetic recorded upon an excitation of the $\left[\mathrm{Fe}(\mathrm{phen})_{3}\right]^{2+}$ complexes by a $\sim 100 \mathrm{fs}$ laser centered at $\lambda=320 \mathrm{~nm}$ is almost similar to the one recorded upon an excitation of the same solution by a $\sim 100 \mathrm{fs}$ laser centered at $\lambda=500 \mathrm{~nm}$. Hence, one cannot either discard LS $\rightarrow$ HS nor HS $\rightarrow$ LS photo-switching of the complexes. We therefore consider, the transient absorption (resp. bleaching) recorded at $\lambda \sim 500 \mathrm{~nm}$ (resp. $\lambda \sim 450 \mathrm{~nm}$ and $\lambda \sim 550 \mathrm{~nm}$ ) indicates the evolution of the average number of complexes promoted from the HS to LS state (resp. LS to HS state). 

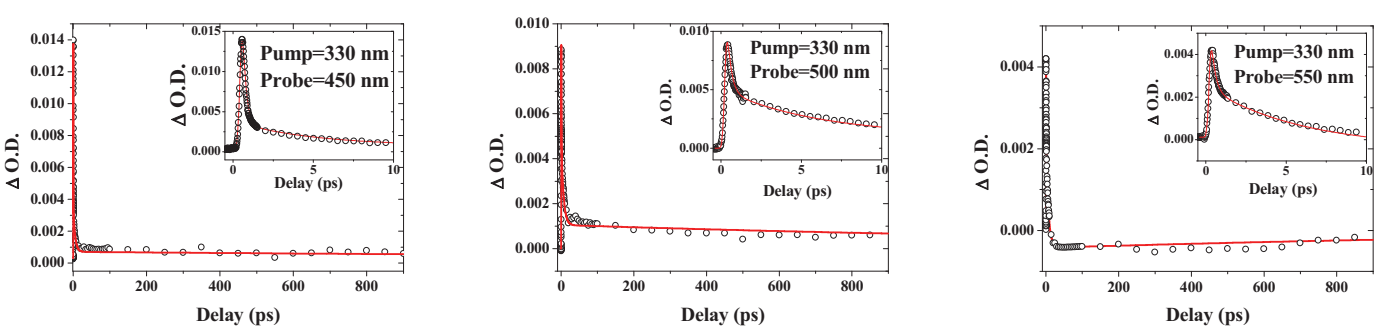

Fig. 2: Kinetic traces recorded at different probe wavelengths $(450,500$ and $550 \mathrm{~nm})$. The solid lines are the fits of the kinetic.

To confirm this hypothesis, we recorded the evolutions of the optical density of the $\left[\mathrm{Fe}\left(2 \mathrm{CH}_{3}\right.\right.$ phen $\left.)_{3}\right]^{2+}$ excited by a $\sim 100 \mathrm{fs}$ pulse centered at $\lambda=330 \mathrm{~nm}$ and probed with $\sim 100 \mathrm{fs}$ pulses centered at $\lambda=450,500$ and $550 \mathrm{~nm}$ (Figure 2). As shown in Figure 2, the kinetics of the recorded signals could be nicely fitted. Interestingly for both probe pulses centered at $\lambda=450$ and $550 \mathrm{~nm}$, we could fit the data using the same time constants: $250 \pm 40 \mathrm{fs}, 7.0 \pm 0.5 \mathrm{ps}$ and $3.6 \pm 0.2 \mathrm{~ns}$. The latter are very close to the ones we recorded for the LS to HS state photo-switching of [ $\left.\mathrm{Fe}(\mathrm{phen})_{3}\right]^{2+}$ complexes [6]. The first relaxation steps were identified as a simple ${ }^{1} \mathrm{MLCT} \rightarrow{ }^{3} \mathrm{MLCT} \rightarrow{ }^{5} \mathrm{~T}_{2} \rightarrow{ }^{1} \mathrm{~A}_{1}$ cascade from the initially excited state [3]. In our case, upon excitation of the ${ }^{1} \mathrm{~A}_{1}$ ground state, the ${ }^{1} \mathrm{MLCT} \rightarrow{ }^{3} \mathrm{MLCT}$ transition takes place is less than $100 \mathrm{fs}$. The ${ }^{3} \mathrm{MLCT} \rightarrow{ }^{5} \mathrm{~T}_{2}$ transition occurs in $\sim 250 \mathrm{fs}$ living the complex in a highly vibrationaly excited state that relaxes toward the valley of ${ }^{5} \mathrm{~T}_{2}$ well in $\sim 7 \mathrm{ps}$ and subsequently to the ground state in $\sim 3.6 \mathrm{~ns}$. The latter process cannot account for the population of the LS state recorded in Figure 1d. Moreover, with these previous time constants, we could not fit the data recorded for $\lambda=500 \mathrm{~nm}$. While the increase of the absorption does also occur during the pump-probe pulses temporal overlap, the decrease of the signal was fitted by a tri-exponential decay law with time constants of $200 \pm 30 \mathrm{fs}, 5.1 \pm 0.3 \mathrm{ps}$ and $\sim 3.6 \pm 0.5 \mathrm{~ns}$ respectively. This phenomenon can be accounted if one considers that part of the excited complexes relax as follow: ${ }^{5} \mathrm{MLCT} \rightarrow{ }^{3} \mathrm{~T}_{2} \rightarrow{ }^{1} \mathrm{~A}_{1} \rightarrow{ }^{5} \mathrm{~T}_{2}$. Here again the ${ }^{5} \mathrm{MLCT} \rightarrow{ }^{3} \mathrm{~T}_{2}$ transition takes place is less than $100 \mathrm{fs}$. The ${ }^{3} \mathrm{~T}_{2} \rightarrow{ }^{1} \mathrm{~A}_{1}$ transition occurs in $\sim 200 \mathrm{fs}$ living the complex in a highly vibrationaly excited state that relaxes toward the valley of ${ }^{1} \mathrm{~A}_{1}$ well in $\sim 5 \mathrm{ps}$ and subsequently to the ${ }^{5} \mathrm{~T}_{2}$ in $\sim 3.6 \mathrm{~ns}$.

In conclusion, we have demonstrated that it is indeed possible to study both the LS $\rightarrow \mathrm{HS}$ and HS $\rightarrow$ LS excitation and relaxation processes in a solution of iron(II) complexes. The kinetics and the relaxation pathways of the photo-excited complexes have presented and discussed.

\section{References}

[1] A. Hauser, Top. Curr. Chem. 234, 155 (2004).

[2] J.J. McGarvey, I. Lawthers, K. Heremans, H. Toftlund, J. Chem. Soc.-Chem. Commun, 1575 (1984)

[3] C. Bressler, C. Milne, V. T. Pham, A. ElNahhas, R. M. van der Veen, W. Gawelda, S. Johnson, P. Beaud, D. Grolimund, M. Kaiser, C. N. Borca, G. Ingold, R. Abela, M. Chergui, Science 323, 489 (2009).

[4] E. A. Juban, A. L. Smeigh, J. E. Monat, J. K. McCusker, Coord. Chem. Reviews 250, 1783 (2006)

[5] H.A. Goodwin, R.N. Sylva, Aust. J. Chem 21, 83 (1968).

[6] J. Tribollet, G. Galle, G. Jonusauskas, D. Deldicque, M. Tondusson, J.F. Letard, E. Freysz, Chem. Phys. Lett. 513, 42 (2011). 